Open Access

Original Article

\title{
Variability in the therapeutic response of Metformin treatment in patients with type 2 diabetes mellitus
}

\author{
Maryam Rashid', Muhammad Shahzad², \\ Saqib Mahmood ${ }^{3}$, Khurshid Khan ${ }^{4}$
}

\begin{abstract}
Objective: To assess the glycemic response of metformin in patients with Type-2 Diabetes Mellitus (T2DM) as well as to see its association with reductions in BMI and GIT intolerance.

Methods: This Quasi, Experimental study was conducted at Jinnah-Allama Iqbal Institute of Diabetes and Endocrinology (JAIDE) Jinnah Hospital, Lahore from $1^{\text {st }}$ March 2016 to $30^{\text {th }}$ September 2016. Newly diagnosed T2DM patients were given metformin for duration of three months and later on they were categorized into Responders and Non-Responders on the basis of HbA1C (A1C) reductions, which were estimated by Hemoglobin (A1C) analyzer (TD4611A TAIDoc Tech. Taiwan) through photometry. Similarly, baseline BMI and BMI after three months therapy with metformin was also recorded.

Results: Among total of 200 patients, $40.5 \%$ of the patients were classified as Non-Responders whereas; $59.5 \%$ of the patients as Responders. The baseline BMl $\left(26.09 \mathrm{~kg} / \mathrm{m}^{2}\right)$ was also decreased significantly after metformin therapy $\left(25.40 \mathrm{~kg} / \mathrm{m}^{2}\right)$. It was found that metformin reduced the $\mathrm{A} 1 \mathrm{C}$ in all the patients. However, the glycemic control was much better in patients with higher baseline $\mathrm{A} 1 \mathrm{C}(1.13 \% \pm 0.08)$ as compared to lower baseline levels $(0.61 \% \pm 0.07)$. Regarding GIT intolerance, 140 patients lacked the symptoms, out of which $60.7 \%$ were responders and $39.3 \%$ were non-responders.

Conclusions: Metformin lead to improvement in glycemic control in $59.5 \%$ of newly diagnosed T2DM patients after taking metformin for three months but in $40.5 \%$ it did not which may be because of combined effects of various gene polymorphisms and their interaction with non-genetic factors. Metformin reduced the BMI in all the patients; however, BMI lowering activity of metformin was same regardless of its effect on HbA1C. Moreover, the signs and symptoms of GIT intolerance did not differ between the two groups.
\end{abstract}

KEYWORDS: Type-2 Diabetes Mellitus, Metformin, Glycemic Response, Body Mass Index, GIT Intolerance.

doi: https://doi.org/10.12669/pjms.35.1.100

How to cite this:

Rashid M, Shahzad M, Mahmood S, Khan K. Variability in the therapeutic response of Metformin treatment in patients with type 2 diabetes mellitus. Pak J Med Sci. 2019;35(1):71-76. doi: https://doi.org/10.12669/pjms.35.1.100

This is an Open Access article distributed under the terms of the Creative Commons Attribution License (http://creativecommons.org/licenses/by/3.0), which permits unrestricted use, distribution, and reproduction in any medium, provided the original work is properly cited.

\section{INTRODUCTION}

Type-2 diabetes mellitus (T2DM) is the predominant form of diabetes and accounts for at least $90 \%$ of all cases of diabetes mellitus. ${ }^{1}$ It

Correspondence:

Muhammad Shahzad,

Head of Department of Pharmacology,

University of Health Sciences,

Lahore, Pakistan.

E-mail: shahzad912@hotmail.com, shahzad912@uhs.edu.pk

* Received for Publication:

September 26, 2018

* Revision Received:

* Revision Accepted: *
November 5, 2018

November 8, 2018 is characterized by the insulin resistance due to reduced sensitivity of insulin in the body tissues along with decreased insulin production. Insulin receptors become inefficient in receiving insulin and providing it to the body tissues ultimately accumulating the glucose in blood and in various parts of body. ${ }^{2}$

Worldwide prevalence of diabetes in adults was estimated to be $4.0 \%$ in 1995 and is expected to rise to $5.4 \%$ by the year 2025. Pakistan will have an escalation from 4.3 million in 1995 to an anticipated 14.5 million in the year 2025. ${ }^{3}$ As per International Diabetes Federation (IDF) report 2015, in Pakistan, 7 million people are diabetics. ${ }^{4}$ The mean 
prevalence of type 2 diabetes mellitus in Pakistan was previously $11.77 \%$ which has now increased to $26.3 \% .5,6$

Metformin is extensively used for treating T2DM as first-line monotherapy. In conjunction with diet, metformin reduces fasting glucose concentration by 2.78 to $3.90 \mathrm{mmol} / \mathrm{L}$ ( 50 to $70 \mathrm{mg} / \mathrm{dL}$ ), which corresponds to $1.3 \%$ to $2.0 \%$ reduction in $\mathrm{HbA} 1 \mathrm{c}$ values. ${ }^{7,8}$ Additionally, it is known to prevent or delay the onset of T2DM in those with pre-diabetes. Its major mode of action is to reduce hepatic glucose production, which is increased at least two folds in patients with T2DM. All these effects finally lead to increase in blood glucose levels in diabetic patients. ${ }^{9}$

Metformin is associated with weight loss when used to treat diabetes and thus differs from a number of other anti-diabetic medications that are associated with weight stability or gain. ${ }^{10}$ Metformin treatment is frequently associated with GI sideeffects $(20-30 \%$ of patients). Common metformin GI symptoms include nausea, diarrhea, vomiting, bloating, dyspepsia, metallic taste, abdominal pain, abdominal cramps and/or changes in intestinal motility, leading to loose stools and overt diarrhea that becomes uncontrollable sometimes. The pathophysiology of metformin induced GI intolerance is unclear, however it is hypothesized that GI intolerance is related to high concentration of metformin in the intestine after oral administration of the drug. ${ }^{11}$

The current study was conducted to determine the efficacy of metformin in lowering $\mathrm{HbA} 1 \mathrm{C}$. The decrease in $\mathrm{HbA1C}$ could be considered as a criterion for response to metformin. It highlights the need for personalized medications to maintain tight glycemic control.

\section{METHODS}

This Quasi, Experimental study was conducted in Jinnah-Allama Iqbal Institute of Diabetes and Endocrinology (JAIDE) Jinnah Hospital, Lahore from $1^{\text {st }}$ March 2016 to $30^{\text {th }}$ May 2016. Two hundred (200) newly diagnosed patients with T2DM (age 35 to 60 years, metformin naive patients with HbA1C 7-9\%) were recruited in the study. Type2 diabetic patients were diagnosed on one of the following criteria; Fasting ( 8 hour or longer fast) glucose $\geq 126 \mathrm{mg} / \mathrm{dl}$ ( $\geq 7.0 \mathrm{mmol} /$ liter), Two hours glucose $\geq 200 \mathrm{mg} / \mathrm{dl}$ ( $\geq 11.1 \mathrm{mmol} /$ liter) during an oral glucose tolerance test (OGTT), Non-fasting plasma glucose $>200 \mathrm{mg} / \mathrm{dl}$ or $\mathrm{HbA1c} \geq 6.5 \%$. Patients having abnormal renal functions (raised creatinine levels $\geq 1.5 \mathrm{mg} / \mathrm{dl}$ in males and $\geq$
$1.4 \mathrm{mg} / \mathrm{dl}$ in females), cirrhosis of liver, congestive heart failure, pregnancy, peptic ulcer disease and inflammatory bowel disease were excluded from the study. The sample size was calculated by WHO software based on S.K Lwanga and Lameshow. The following formula has been used, keeping the confidence (CI) level equal to $95 \%$ and the margin of error equal to $6 \%$.

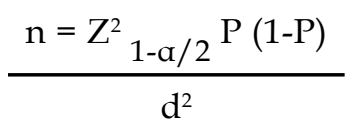

$$
\begin{aligned}
\mathrm{Z}^{2} 1-\mathrm{a} / 2 & =\text { for } 95 \% \text { confidence level } & = & 1.96 \\
\mathbf{P} & = & = & \text { Prevalence } \\
\mathbf{d} & = & \text { Margin of error } & =6 \% \\
\mathbf{n} & =\text { Sample Size } & = & 260
\end{aligned}
$$

Initially a total of 260 type 2 diabetic patients were included in the study. However, because of inclusion criteria and later stage drop out of patients, the sample size was reduced to 200 in each group.

All the participants provided written informed consent and subjects were adequately informed of the aims, methods, sources of funding, any possible conflicts of interest, institutional affiliations of the researcher, the anticipated benefits and potential risks of the study and the discomfort it may entail and post-study provisions. These protocols were approved by the Ethics Committee of University of Health Sciences, Lahore. Additionally, the research and recruitment protocols were carried out according to the Ethical Principles for Medical Research involving Human Subjects adopted in the Declaration of Helsinki by the World Medical Association. ${ }^{12}$ Information obtained in the interview was recorded on standardized data collection forms. Convenient sampling was done for recruitment of patients.

Metformin was given starting with low dose of $500 \mathrm{mg}$ daily and then upgraded to full dose (2000 $\mathrm{mg}$ /day) with following schedule: $500 \mathrm{mg}$ once a day for 5 days followed by $1000 \mathrm{mg}$ once a day for five days and finally $1000 \mathrm{mg}$ twice daily, if no side effects were observed. Patients were monitored for a 12-week period. Patients were asked to come for follow up after six week to see compliances.

Blood sampling for A1C estimation was done twice in the study period, first at the beginning of the metformin therapy and the second one; three months after metformin therapy. On the basis of A1C reduction by metformin, patients were categorized into Responders and NonResponders. 
There is no accepted criterion in the clinical cut-off point to divide patients into Responders and NonResponders. Thus, we selected the criteria based on our clinical experiences and previous studies as follows: Responders and Non-Responders (patients whose $\mathrm{HbA1c}$ levels had decreased by $\geq 0.8 \%$ or $<0.8 \%$ from the baseline within three months of metformin therapy respectively)..$^{13,14}$

A1C was measured by Haemoglobin (A1C) analyzer (TD4611A TAIDoc Tech. Taiwan) through photometry. The reagent utilizes antigen-antibody reaction to directly determine the glycated hemoglobin in the blood.

The patients were inquired about the adverse effects of metformin which mainly included nausea, diarrhoea, dyspepsia or abdominal pain on each visit. GIT intolerance was said to be present if any one of these symptoms appeared one week after therapy with metformin. ${ }^{15} \mathrm{BMI}$ before and after three months of metformin therapy was recorded.

Data Analysis: Baseline median of the A1C and BMI of the patients was recorded along with the A1C after three months' treatment as the data was not normally distributed. Independent $t$-testing was done to calculate the differences in the mean of the A1C and BMI within the groups. The frequency of GIT intolerance was calculated in overall cases and then in the response groups. Association of GIT intolerance and the cases was measured using chi-square test ( $\mathrm{p}$ value $0.5 \%, \mathrm{x}^{2}=0.436$ ).

\section{RESULTS}

Out of 200, 119 patients were Responders whereas, 81 were found to be Non-Responders. The patients with A1C decrease of $\geq 0.8 \%$ were grouped as Responders and those with lesser reduction of $<8 \%$ were grouped as Non-Responders to metformin therapy.

The median age of the patients was 49 years whereas in Responders it was 50 years and in Non-Responders it was 49 years. More females $69 \%(n=138)$ were affected in the present study as compared to males $31 \%(n=62)$. Amongst all the females, 88 (64\%) were Responders and 50 (36\%) were Non-Responders. In case of males, $56 \%(n=32)$ were Responders and $48 \%(n=30)$ were NonResponders. Though females were more in the study group but the gender distribution was not different in the two response groups significantly. Study showed that $54 \%$ patients had positive family history for diabetes whereas $36 \%$ patients had no family history of diabetes.

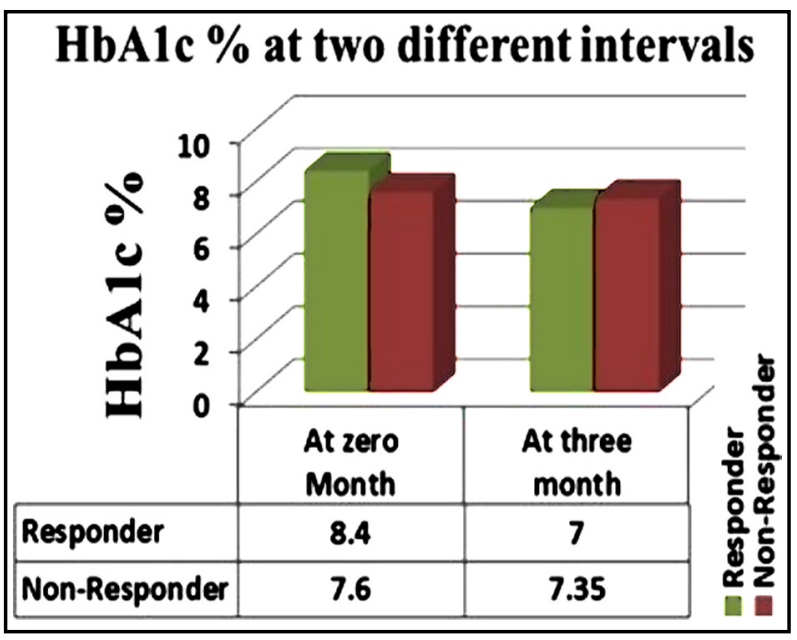

Fig.1: Median value of A1C at the start and after three months of Metformin therapy in Responders $(\mathrm{N}=119)$ and Non-Responders $(\mathrm{N}=81)$.

The median value of baseline A1C in Responders and Non-Responders was 8.4 and 7.6 respectively (Fig.1). The difference in the median of the two groups at the start of the metformin therapy was significant. The median value of A1C after three months of metformin therapy was seven and 7.35 in Responders in Non-Responders, respectively and the difference in the median of the two response groups was statistically significant.

In the present study the efficiency of metformin in reducing the A1C was analyzed. Group-1 included the patients with the $\mathrm{A} 1 \mathrm{C}<8 \%$ and the Group-2 included patients with relatively A1C of $\geq 8 \%$. The difference between the mean reductions in the A1C within each group was found to be statistically significant ( $p$ value $<0.0001$ ). The more the baseline $\mathrm{A} 1 \mathrm{C}$, the more was the decrease in A1C by metformin. The mean value of A1C in Group-1 and Group-2 at the start of the metformin therapy

Table-I: Differences in HbA1C (\%) in Group-1 and Group-2 (N=200).

\begin{tabular}{lcc}
\hline A1C $(\%)$ & $\begin{array}{c}\text { Group-1* } \\
(\text { Mean } \pm \text { SEM })\end{array}$ & $\begin{array}{c}\text { Group-2* } \\
(\text { Mean } \pm \text { SEM })\end{array}$ \\
\hline Baseline & $7.50 \pm 0.030$ & $8.70 \pm 0.033$ \\
After 3 months & $6.88 \pm 0.077$ & $7.57 \pm 0.08$ \\
Decrease in A1C & $0.61 \pm 0.07$ & $1.13 \pm 0.08$ \\
$\quad$ within a group & \multicolumn{2}{c}{$0.51 \pm 0.11$} \\
$\begin{array}{l}\text { Difference between } \\
\text { two groups }\end{array}$ & \multicolumn{2}{c}{$<0.0001^{*}$} \\
p-value & \multicolumn{2}{c}{} \\
\hline
\end{tabular}

*Group-1= Individuals with A1C $\leq 8 \%$,

*Group-2= Individuals with A1C $>8 \%$

${ }^{*} \mathrm{p}$-value significant $<0.05$. 


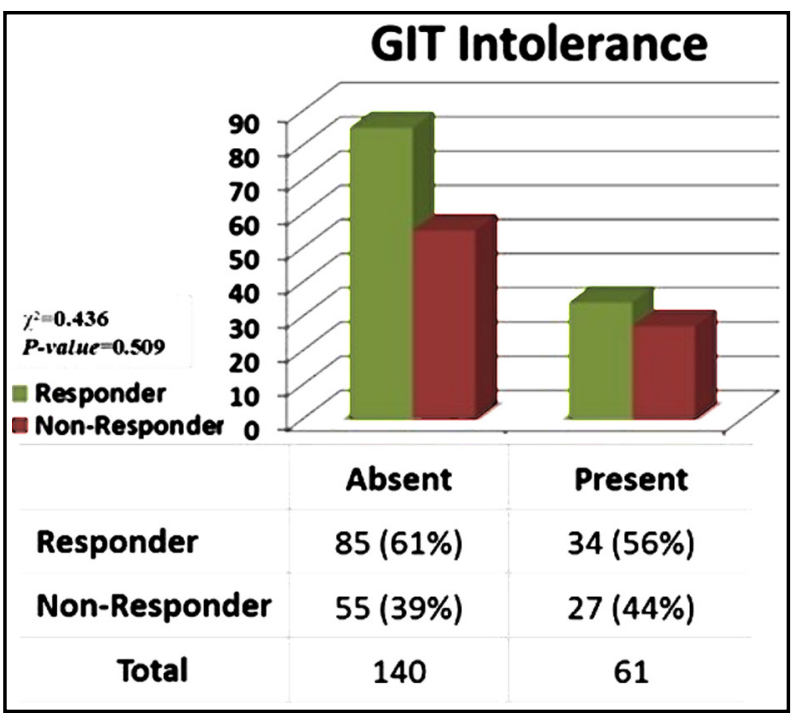

Fig.2: The frequency of GIT intolerance in

Responders $(\mathrm{N}=119)$ and NonResponders $(\mathrm{N}=81)$ and the association of the two variables.

and three months after and the difference in the mean values of the two groups are given in Table-I.

The median BMI of the diabetic patients at the start of metformin therapy was $26.09 \mathrm{~kg} / \mathrm{m}^{2}$ whereas the median BMI after three months' metformin therapy was $25.40 \mathrm{~kg} / \mathrm{m}^{2}$. The difference between the median BMI before and after the metformin therapy was statistically different with pvalue 0.00 showing the reduction of BMI after treatment. The BMI between the two groups was not statistically different showing that metformin lowering activity of BMI was same for the two response groups (Table-II).

After receiving metformin, about 61 patients out of 200 reported GI side effects; the difference between responders $(n=34,56 \%)$ and non-responders $(n=27$, $44 \%)$ was not statistically significant (P-value $=$ 0.509) (Fig.2).

\section{DISCUSSION}

Type-2 diabetes mellitus is the most prevalent form of diabetes and metformin is the first line drug for its treatment. Regardless of its widespread use, $35 \%$ of patients fail to reach initial target glycaemic control with metformin due to variable drug response. ${ }^{16}$ In the present study, 59.5\% patients were categorized as Responders and $40.5 \%$ as NonResponders to metformin on the basis of reductions in A1C. If categorization of patients is compared in terms of response, similar study was done on South Indian newly diagnosed T2DM patients where $76 \%$ of the patients were labeled as Responders and 23\%
Table-II: The mean and SEM of BMI before and after metformin therapy and the difference in two response groups and within the group $(\mathrm{N}=200)$.

\begin{tabular}{lcc}
\hline BMI kg/m & $\begin{array}{c}\text { Responders } \\
(\text { Mean } \pm \text { SEM }) \\
(n=81)\end{array}$ & $\begin{array}{c}\text { Non-Responders } \\
(\text { Mean } \pm S E M) \\
(n=119)\end{array}$ \\
\hline Baseline & $24.87 \pm 0.44 \mathrm{~kg} / \mathrm{m}^{2}$ & $25.24 \pm 0.55 \mathrm{~kg} / \mathrm{m}^{2}$ \\
After 3 months & $24.63 \pm 0.39 \mathrm{~kg} / \mathrm{m}^{2}$ & $24.85 \pm 0.50 \mathrm{~kg} / \mathrm{m}^{2}$ \\
Decrease in BMI & $0.24 \pm 0.11 \mathrm{~kg} / \mathrm{m}^{2}$ & $0.39 \pm 0.20 \mathrm{~kg} / \mathrm{m}^{2}$ \\
within a group & & $0.00^{*}$ \\
p-value for decrease & $0.00^{*}$ & $0.15 \pm 0.04 \mathrm{~kg} / \mathrm{m}^{2}$ \\
$\begin{array}{c}\text { Difference between } \\
\text { two groups }\end{array}$ & \multicolumn{2}{c}{0.68} \\
p-value for difference
\end{tabular}

${ }^{*}$ p-value significant $<0.05$.

as Non-Responders. ${ }^{8}$ However, the proportion of Nonresponders was greater in our study but this variability in non-responsiveness may be attributed to other factors like genetic changes, duration of diabetes, or compliance of patients which were not taken in account in this study.

In the present study it was found that metformin effectively reduced the BMI of the patients after three months of therapy and these were statistically significant results which were not due to chance. The reduction in the response group was also significant but the decrement was not different amongst the two response groups. This finding was in concordance to the previous research done on white Americans as they found strong association of BMI with the patients. They found that reduction in BMI was more in Responder group as compared to Non-Responder group..$^{17}$ Another study done on German population in 2013 also showed discordant results to the present study. ${ }^{18}$ The same results were found in a research done on the Australian population in 2006 and they found that metformin therapy had no effect in reducing BMI of the patient whether they are Responders or Non-Responders. ${ }^{19}$

Tarasova and her colleagues found that BMI was not associated to any of the response group in Latvian population and the BMI was higher than the present study. However, more attention should be paid towards classifying patients according to the degree of obesity in proportion to total body mass, as well as to the degree of abdominal obesity. ${ }^{20}$

GIT intolerance is one of the major side effects of metformin which leads to premature discontinuation of therapy in $4-10 \%$ of cases. ${ }^{20}$ The results of current study showed that GIT 
intolerance was not associated with the response group and these results are in contradiction to the study done on population from North Caucasia, North Africa and Sub-Sahara African ancestry. They found significant effect of metformin therapy in producing GIT intolerance. ${ }^{21}$ Whereas, Laura and her colleagues found no association between metformin therapy and the GIT intolerance. ${ }^{22}$ The risk factors for metformin intolerance should be identified like the concomitant use of anti-diarrheal drugs or the patients who have pre-existing GI problems.

Patients with initial $\mathrm{HbA} 1 \mathrm{C}$ levels equal or more than $8 \%$ showed more decrease in these levels than those having $\mathrm{HbA} 1 \mathrm{C}$ less than $8 \%$. This study supports the finding of a meta-regression analysis providing a numerical estimate of an effect that has been commented on by previous authors: higher baseline A1C levels are associated with greater declines in $\mathrm{HbA} 1 \mathrm{C}$ with metformin therapy and this is also supported by other studies. ${ }^{23}$

Limitations of the study: It included using simple questioning techniques rather than validated quality of life measures to record GI adverse effects and patients' satisfaction; not evaluating GI side effects after continued therapy; if it can improve GI compliance or not. The patients were enrolled from only one diabetic center hence limiting the diversification of the patients.

\section{CONCLUSION}

This study revealed that, decrease in $\mathrm{HbA1c}$ levels by more than $0.8 \%$ from baseline could be considered a criterion for response to metformin. In addition, few patients were non-responders to metformin therapy, which may be because of combined effects of various gene polymorphisms in their interaction with non-genetic factors. Metformin reduced the BMI in all the patients; however, BMI lowering activity of metformin was same regardless of its effect on $\mathrm{HbA1C}$. Moreover, the signs and symptoms of GIT intolerance did not differ between the two groups.

\section{ACKNOWLEDGEMENTS}

We would like to thank the department of Diabetes and Endocrinology, Jinnah hospital for providing access to the Patients and samples.

Declaration of interest: None.

Source of funding: None.

Disclaimer: None.

\section{REFERENCES}

1. Soumya D, Srilatha B. Late stage complications of diabetes and insulin resistance. J Diabetes Metab. 2012;2(9):1-7.

2. Bloomgarden ZT, Dodis R, Viscoli CM, Holmboe ES, Inzucchi SE. Lower baseline glycemia reduces apparent oral agent glucose-lowering efficacy a meta-regression analysis. Diabetes Care. 2006;29(9): 2137-2139. doi: 10.2337/dc06-1120.

3. Basit A, Danish Alvi SF, Fawwad A, Ahmed K, Yakoob Ahmedani $\mathrm{M}$, et al. Temporal changes in the prevalence of diabetes, impaired fasting glucose and its associated risk factors in the rural area of Baluchistan. Diabetes Res Clin Pract. 2011;94(3):456-462. doi: 10.1016/j. diabres.2011.08.009.

4. Zafar J, Bhatti F, Akhtar N, Rasheed U, Bashir R, Humayun S. Prevalence and risk factors for diabetes mellitus in a selected urban population of a city in Punjab. J Pak Med Assoc. 2011;61:40-47.

5. S. A. Meo, I. Zia, I. A. Bukhari, Arain SA. Type 2 diabetes mellitus in Pakistan: Current prevalence and future forecast. J Pak Med Assoc. 2016;66(12):1637-1642.

6. Basit A, Fawwad A, Qureshi H, Shera AS. Prevalence of diabetes, pre-diabetes and associated risk factors: second National Diabetes Survey of Pakistan (NDSP), 2016-2017. BMJ open. 20188;8(8):e020961.

7. Nathan DM, Buse JB, Davidson MB, Heine RJ, Holman $R R$, Sherwin R, et al. Management of hyperglycemia in type 2 diabetes: A consensus algorithm for the initiation and adjustment of therapy a consensus statement from the American Diabetes Association and the European Association for the study of diabetes. Diabetes Care. 2006;29(8):1963-1972. doi: $10.2337 /$ dc06-9912.

8. Umamaheswaran G, Praveen RG, Arunkumar AS, Das AK, Shewade DG, Adithan C. Genetic analysis of OCT1 gene polymorphisms in an Indian population. Indian J Hum Genet. 2011;17(3):164-168. doi: 10.4103/09716866.92094 .

9. Kirpichnikov D, Mcfarlane SI, Sowers JR. Heart failure in diabetic patients: utility of $\beta$ blockade. J Card Fail. 2003;9(4):333-344.

10. Bray GA, Ryan DH. Medical therapy for the patient with obesity. Circulation 2012;125(13):1695-1703. doi:10.1161/ CIRCULATIONAHA.111.026567.

11. Hermans $M$, Ahn SA, Rousseau M. What is the phenotype of patients with gastrointestinal intolerance to metformin? Diabetes Metab. 2013;39(4):322-329. doi: 10.1016/j.diabet.2013.05.005.

12. World Medical Association Declaration of Helsinki: ethical principles for medical research involving human subjects. JAMA. 2013;310(20):2191-2194. doi: 10.1001/ jama.2013.281053

13. Shikata E, Yamamoto R, Takane H, Shigemasa C, Ikeda T, Otsubo K, et al. Human organic cation transporter (OCT1 and OCT2) gene polymorphisms and therapeutic effects of metformin. J Hum Genet. 2007;52(2):117-122. doi: 10.1007/ s10038-006-0087-0.

14. Tkac I, Javorsky M, Klimcakova L, Zidzik J, Gal'a I, Babjakova E, et al. A pharmacogenetic association between a variation in calpain 10 (CAPN10) gene and the response to metformin treatment in patients with type 2 diabetes. Eur J Clin Pharmacol. 2015;71(1):59-63. doi: 10.1007/s00228-014-1774-y. 
15. Siavash M, Tabbakhian M, Sabzghabaee AM, Razavi N. Severity of Gastrointestinal Side Effects of Metformin Tablet Compared to Metformin Capsule in Type 2 Diabetes Mellitus Patients. J Res Pharm Pract. 2017;6(2):73-76. doi: [10.4103/jrpp.JRPP_17_2]

16. Goswami S, Yee SW, Stocker S, Mosley JD, Kubo M, Castro R, et al. Genetic variants in transcription factors are associated with the pharmacokinetics and pharmacodynamics of metformin. Clin Pharmacol Ther. 2014;96(3):370-379. doi: 10.1038/clpt.2014.109.

17. Dujic T, Zhou K, Donnelly LA, Tavendale R, Palmer CN, Pearson ER. Association of organic cation transporter 1 with intolerance to metformin in type 2 diabetes: a GoDARTS study. Diabetes. 2015;64(5):1786-1793. doi: 10.2337/db14-1388.

18. Seifarth C, Schehler B, Schneider H. Effectiveness of metformin on weight loss in non-diabetic individuals with obesity. Exp Clin Endocrinol Diabetes. 2013;121(01):27-31. doi: 10.1055/s-0032-1327734.

19. Ong CR, Molyneaux LM, Constantino MI, Twigg SM, Yue DK. Long-term efficacy of metformin therapy in nonobese individuals with type 2 diabetes. Diabetes Care. 2006;29(11):2361-2364. doi:10.2337/dc06-0827.

20. Tarasova L, Kalnina I, Geldnere K, Bumbure A, Ritenberga $\mathrm{R}$, Nikitina-Zake L, et al. Association of genetic variation in the organic cation transporters OCT1, OCT2 and multidrug and toxin extrusion 1 transporter protein genes with the gastrointestinal side effects and lower BMI in metformintreated type 2 diabetes patients. Pharmacogenet Genomics. 2012;22(9):659-666. doi:10.1097/FPC.0b013e3283561666.
21. Nathan DM, Buse JB, Davidson MB, Heine RJ, Holman $R R$, Sherwin $R$, et al. Management of hyperglycemia in type 2 diabetes: A consensus algorithm for the initiation and adjustment of therapy a consensus statement from the American Diabetes Association and the European Association for the study of diabetes. Diabetes Care. 2006;29(8):1963-1972.

22. Mccreight LJ, Bailey CJ, Pearson ER. Metformin and the gastrointestinal tract. Diabetologia. 2016;59(3):426-435. doi: 10.1007/s00125-015-3844-9.

23. Van Gaal L, Scheen A. Weight management in type 2 diabetes: current and emerging approaches to treatment. Diabetes Care. 2015;38(6):1161-1172. doi:10.2337/dc14-1630.

\section{Author`s Contribution:}

RM: Conceived the Idea, Data Collection, Manuscript Writing, Data analysis and preparation of the article.

SM: Conceived the Idea, Supervise the Study, Manuscript Writing and preparation of the article.

KK: Data collection.

MS: Supervise the study.
Authors:

1. Maryam Rashid, Department of Pharmacology,

2. Muhammad Shahzad, Department of Pharmacology,

3. Saqib Mahmood, Department of Human Genetics and Molecular Biology,

4. Khurshid Khan, Department of Medicine and Endocrinology, Jinnah Hospital, Lahore, Pakistan.

1-3: University of Health Sciences, Lahore, Pakistan. 